An Unequal and Inhumane Society: Perceived Inequality Enlarges the Perceived Humanity Gap between Poor and Rich Groups

Mario Sainz ${ }^{1 *}$, Rocío Martínez ${ }^{2}$, Juan Matamoros-Lima², Miguel Moya², and Rosa RodríguezBailón ${ }^{2}$

${ }^{1}$ School of Psychology, Pontificia Universidad Católica de Chile, Chile. ${ }^{2}$ Department of Social Psychology, Faculty of Psychology, University of Granada, Spain.

*Corresponding author information: Mario Sainz, Campus San Joaquín - Avda.Vicuña Mackenna 4860, Macul, Santiago, Chile (e-mail: mario.sainz@uc.cl).

Funding: This research was funded by the Agencia Nacional de Investigación y Desarrollo ANID - through the program FONDECYT Postdoctorado 2020 [Project number 3200031: Mario Sainz].

Data availability statement: Data and materials can be found online: https://osf.io/b5qwf/?view_only=c33459fdc5474fc28749087242b2c711

Acknowledgements: We acknowledge support from the Centre for Social Conflict and Cohesion Studies - COES (ANID/FONDAP/15130009).

Word count: 9957. 


\title{
An Unequal and Inhumane Society: Perceived Inequality Enlarges the Perceived Humanity Gap Between Poor and Rich Groups
}

\author{
Abstract (145 words) \\ In the present project, we analyze how perceptions of economic inequality cause \\ individuals to recognize that people tend to dehumanize poor people and humanize rich people \\ within their societies. We observed this tendency in our initial pair of correlational studies. \\ Furthermore, in two experimental studies, we found that people recognize that poor people are \\ more strongly dehumanized and rich people are more strongly humanized when economic \\ inequality is perceived as high rather than low. In a final pair of experimental studies, we \\ compare the effects of (a) the degree of perceived economic inequality and (b) the degree of \\ perceived economic development in a society. Our results indicate that the metadehumanization \\ of poor groups prevailed most strongly in societies perceived as unequal and underdeveloped \\ whereas societies perceived as more equal and developed enhance their ascription of \\ metahumanity to rich people. Implications of these findings are discussed. \\ Keywords: economic inequality, metadehumanization, socioeconomic status.
}


Differences in objective indicators such as the economic growth of a society, its level of globalization, or its gross domestic product influence people's lives and attitudes (Andersen \& Fetner, 2008; Caluori et al., 2020). For instance, people living in economically unequal societies (i.e., those with higher Gini index scores) more frequently face health and psychological problems such as obesity and lower life expectancy (Patel et al., 2018; Pickett \& Wilkinson, 2015; Pickett et al., 2005) or greater risk of security threats due to higher crime levels (Elgar \& Aitken, 2011; Rufrancos et al., 2013). Furthermore, subjective perceptions of economic disparities also influence people's lives and experiences (Dawtry et al., 2015). For example, higher perceptions of economic inequality are associated with weakened social ties because people perceive an individualistic social climate (Sánchez-Rodríguez et al., 2019) or trust each other less (Fiske et al., 2012; Graafland \& Lous, 2018; Uslaner \& Brown, 2005).

Additionally, those at the bottom of a society in socioeconomic terms are perceived as less developed or less human than those at the top (Sainz, Martínez, Moya, \& Rodríguez-Bailón, 2019). Importantly, this tendency to consider poor people as less evolved or more irrational than rich people facilitates the rationalization of the income gap between them (Sainz, Loughnan, et al., 2020; Sainz, Martínez, Rodríguez-Bailón, \& Moya, 2019; Sainz, Martínez, Sutton, et al., 2020). However, it remains unclear whether certain contextual factors, such as the perceived level of economic inequality within a society, could cause people to perceive the differential attribution of humanity to the "haves" and "have-nots" in their society. Thus, in this project, we aimed to identify the extent to which perceived economic inequality in everyday contexts causes people to recognize (i.e., increases their metaperception) that poor people are dehumanized and rich people are humanized within their society.

\section{Economic Inequality and Social Perception of Poor and Rich Groups}


The perception of economic inequality in everyday life, which can be understood as daily experiences regarding the unequal distribution of resources among members of a society (GarcíaCastro et al., 2019), constitutes the starting point from which people evaluate a society's overall inequality level (García-Castro et al., 2021). Perceptions of economic inequality derive from people's interactions and experiences in their social circles (Dawtry et al., 2015). Thus, daily experiences of inequality are created subjectively through social sampling processes (i.e., interactions with relatives and neighbors) and do not necessarily correspond to objective levels of economic inequality within a society. Nevertheless, subjective perceptions of economic inequality can predict other beliefs and actions, such as attitudes toward and tolerance of inequality (Bobzien, 2019; García-Castro et al., 2020).

In particular, the influence exerted by perceptions of economic inequality could also extend to people's attitudes toward those individuals at both extremes of the social ladder. However, few studies have explored how perceptions of inequality trigger stereotypes or justification of existing income gaps. In one such study, Heiserman and Simpson (2017) found that a higher perception of economic inequality within a society correlated with increased belief in a merit gap (i.e., justification of the income gap). This indicates that lack of awareness of inequality affects behaviors toward rich and poor people (Hauser et al., 2019). Along the same lines, high levels of inequality are related to ambivalent stereotypes about poor and rich groups (Durante et al., 2013; Durante \& Fiske, 2017), and those perceptions of inequality are associated with people's assessments of the competence of poor and rich groups (Connor et al., 2020).

Thus, perceptions of inequality, economic development, or wealth might play a key role in determining how people perceive poor and rich groups and the extent to which wealth is a salient social category (Peters et al., 2021). Further, it suggests a tendency to justify income gaps 
through the assumption that economic differences reflect a natural distribution of groups based on their abilities or traits (Sainz, Loughnan, et al., 2020). Due to the considerable social relevance of such attitudes, we consider it crucial to examine whether perceptions of inequality also affect the extent to which people acknowledge the meta-attributed humanity gap between poor people and rich people.

\section{The Dehumanization of Poor and Rich Groups}

The dehumanization of others is a pervasive process that justifies maintaining the status quo (for reviews, see Haslam \& Loughnan, 2014; Haslam \& Stratemeyer, 2016; Vaes et al., 2012). In this sense, previous research has found that it is common to deny the existence of human uniqueness (HU) traits, such as civility and rationality in those individuals or groups who occupy subordinate positions in society, such as immigrants or ethnic minorities (Esses et al., 2008; Goff et al., 2008). The denial of these traits leads people to perceive individuals or groups as closer to animals than to humans, leading ultimately to the mistreatment of the victims of this process (Haslam \& Loughnan, 2014).

In the same vein, people often view groups or individuals with low socioeconomic status (SES) as not fully human in terms of their HU traits. For instance, Loughnan et al. (2014) found that people in various countries associated poor groups with animals such as apes or dogs. Furthermore, in a set of studies using explicit and implicit methodologies, Sainz, Martínez, Moya, and Rodríguez-Bailón (2019) found that low-SES groups are viewed as lacking HU traits compared to high-SES groups. Thus, low-SES groups not only hold a deprived position within society but are also considered inferior in terms of their HU when compared to wealthy groups. Even when high-SES groups are usually considered to be lacking other characteristics of humanity such as human nature traits (e.g., emotional responsiveness; Sainz, Martínez, 
Rodríguez-Bailón, \& Moya, 2019), results seem to indicate a clear relationship between perceived individual or group SES and the attribution of HU traits to the group.

This tendency to ascribe or deny humanity as a function of the SES of individuals or groups is associated with how people understand poverty and wealth (e.g., causal attributions about poverty and wealth). On the one hand, the dehumanization (low HU) of low-SES people can take the form of blaming them for their situation (i.e., internal attributions about poverty) or concluding that they must be wasting what money they have. These attitudes lead to a rejection of redistribution or welfare policies aimed at helping poor people (Sainz, Loughnan, et al., 2020; Sainz, Martínez, Sutton, et al., 2020). On the other hand, humanizing high-SES groups (high human nature) creates the perception that rich people deserve their wealth. This attitude can foster opposition to progressive, redistributionist tax systems (Sainz, Martínez, RodríguezBailón, \& Moya, 2019).

The aforementioned studies explored the consequences of humanizing or dehumanizing groups based on their SES, but prior research has not addressed the variables that can lead people to recognize that poor people are usually dehumanized compared to rich people in modern societies. In this regard, previous research has mainly focused on how a person's considering that others dehumanize the group to which they belong (i.e., metaperception) might reinforce existing conflicts (Kteily et al., 2016) or reduced the well-being of individuals who are more vulnerable (Sainz, Martínez, Moya, et al., 2020). Based on these results, the consequences of a person's group being perceived as less than human by others is, therefore, a process that highly influences interpersonal and intergroup relations. However, recognizing that third groups to which a person or members of their social circle do not belong are also dehumanized might also serve as an important first step in promoting social change. For instance, recognizing that minority 
communities are discriminated against or that refugees' human rights are threatened might help people identify these social issues as problems that need to be addressed.

Therefore, in the present project, we aimed to analyze the extent to which metaperceptions of the dehumanization and humanization of poor and rich groups, respectively, might vary as a function of the individual's perception of socioeconomic conditions such as the level of economic inequality within a society. We based our work on previous research about (a) how the extent to which unequal societies are perceived as competitive and more threatening provides the context in which people praise rich people and depict poor people unfavorably (Cheng et al., 2021; Heiserman \& Simpson, 2017) and (b) people's understanding of humanity (i.e., HU traits) as a hierarchy distributed variable in which the higher a person's SES, the more HU traits they are perceived to possess (Sainz, Martínez, Sutton, et al., 2020). In general, individuals' recognition of inequality might relate to the recognition of a wider humanity gap between poor people and rich people. Specifically, perceived socioeconomic inequality in a person's daily life might be a trigger for recognizing that people tend to dehumanize low-SES groups while humanizing high-SES groups. Thus, individuals who acknowledge a higher level of economic inequality might recognize the ascribed humanity gap between poor and rich groups to a higher extent, whereas individuals that do not recognize economic inequality might deny this tendency to dehumanize one group and humanize the other.

\section{The Present Research}

We designed the studies described in this paper to analyze the influence of the perceived level of economic inequality in daily life on people's recognition of the tendency to dehumanize poor people and humanize rich people in modern societies. Therefore, along this project, we evaluated metaperceptions of dehumanization. We are interested in analyzing how 
acknowledging economic inequality might trigger the extent to which people recognize the dehumanization and humanization of poor and rich people, respectively, within our society. To achieve this purpose, we conducted three pairs of studies in two countries. In Studies 1A and 1B, we analyzed the relationship between the perceived level of economic inequality and the recognition (i.e., metaperception) of the perceived humanity gap between poor and rich groups. In Studies 2A and 2B, we manipulated the level of inequality experimentally (low versus high) to identify differences in the meta-attribution of humanity to poor and rich groups. Finally, in Studies $3 \mathrm{~A}$ and 3B, we implemented a manipulation that combined perceptions of inequality (low versus high) and perceptions of a society's socioeconomic development or wealth (low versus high) to assess changes in the meta-attribution of humanity to poor and rich groups. We received ethical approval from the Ethics Committee for Research of the University of Granada (No 170/CEIH/2016). Data and materials for these studies can be found online at the following link: https://osf.io/b5qwf/?view_only=c33459fdc5474fc28749087242b2c711

\section{Studies 1A and 1B}

Our goal in these preliminary studies was to explore the possible link between perceptions of economic inequality in daily life and the metaperceptions of humanity attributed to poor and rich groups. We conducted these studies in Spain and Mexico. We hypothesized that perceptions of higher economic inequality would negatively predict lower meta-ascription of humanity to poor groups (Hypothesis 1) and positively predict higher meta-ascription of humanity to rich groups (Hypothesis 2). Preregistration can be found online: https://osf.io/7d24q/?view_only=f6bb8014adcf4087bf5e2f23e884ec8e

\section{Method}

\section{Participants}


We computed sample size for small effect size (regression analysis, $f=.03, \alpha=.05,80 \%$ power; Faul et al., 2009) because we did not identify previous studies that linked perceived economic inequality and meta-dehumanization. G-power analysis indicated that we required at least 325 participants. Consequently, we recruited 408 participants (282 females, 124 males, 2 others; $\left.M_{\text {age }}=24.85, S D=7.67\right)$ for the Spanish sample and 404 participants $(233$ females, 157 males, 14 others, $M_{\text {age }}=34.24, S D=13.34$ ) for the Mexican sample.

Spanish participants were contacted through a general university e-mail list that included students, professors, and administrative staff, and we included them in a raffle for a prize of 100 euros. We recruited Mexican participants using referrals among family members of university students, who received course credits in exchange for their participation.

\section{Procedures}

First, participants answered a 12-item questionnaire about economic inequality in everyday life (e.g., "I know people with very different levels of economic status"; Spain $\alpha=.894$; Mexico $\alpha=.917$; García-Castro et al., 2019). Answer choices ranged from 1 (completely disagree) to 7 (completely agree).

Next, as a measure of blatant dehumanization, participants rated the extent to which they thought that poor and rich groups within their society were considered either less evolved (i.e., animal-like) or more evolved (i.e., human-like). As in previous studies (e.g., Fiske et al., 2002), we asked about metaperceptions (i.e., how others in a society perceive rich people and poor people) rather than requesting that the participants report their own perceptions. This procedure is intended to (a) reduce participants' social desirability concerns when presented with a blatant measure of dehumanization and (b) capture the extent to which people recognize the interplay between SES and the attribution of HU traits previously identified in the literature (Sainz, 
Martínez, Moya, \& Rodríguez-Bailón, 2019). Participants rated each group by using a slider that ranged from 0 (least evolved) to 100 (most evolved). Additionally, as in Kteily et al.'s (2015) original procedure, we included some filler groups (e.g., immigrants, entrepreneurs) to conceal our study's aim.

Finally, participants reported their own SES. The Spanish sample used Adler et al.'s (2000) 10-step ladder; in the Mexican sample, we used the monthly household income per person divided into deciles (Kraus \& Keltner, 2009). We then requested demographic information regarding gender, age, and nationality, and we thanked the participants for their cooperation.

\section{Results}

First, we computed descriptive analyses and correlations (see Table 1). Perceptions of economic inequality in everyday life were negatively related to the degree of metahumanity ascribed to poor people and positively related to that ascribed to rich people. Moreover, the results highlighted the metaperceived humanity gap between poor, which were seems as less evolved, and rich groups, which were seems as more evolved in both the Spanish sample, $t(407)=-31.13, p<.001, d=2.27$, and the Mexican sample $t(403)=-28.70, p<.001, d=2.12$.

Second, we ran a regression analysis to test our main predictions (see Table 2). The results indicated that perceived economic inequality negatively predicted the degree of metahumanity ascribed to poor people (Hypothesis 1) and positively predicted that attributed to rich people (Hypothesis 2). The results remained significant even when we controlled for participants' SES, whether assessed subjectively, as in Spain, or objectively, as in Mexico. For complementary analyses and additional information about the studies, please see the supplementary information. 


\section{Table 1}

Descriptive Results and Correlations Between the Measures in Studies $1 A$ (Spain) and $1 B$ (Mexico)

1. Perceived economic inequality

2. Humanity meta-attributed to the poor

3. Humanity meta-attributed to the rich

\begin{tabular}{cccccc} 
Mean $(S D)$ & 1 & 2 & 3 & 4 & Mean $(S D)$ \\
\hline $6.07(1.06)$ & - & $-.110^{*}$ & $.130^{*}$ & $.099^{*}$ & $5.70(1.03)$ \\
$39.23(22.61)$ & $-.112^{*}$ & - & $-.094^{\dagger}$ & -.068 & $35.10(20.00)$ \\
$81.93(17.26)$ & $.140^{*}$ & $-.109^{*}$ & - & -.005 & $76.76(16.40)$ \\
$5.43(2.65)$ & .058 & -.085 & .048 & - & $6.23(1.32)$
\end{tabular}

4. Participants' socioeconomic status $5.43(2.65)$ $.058-085 \quad .048$ $6.23(1.32)$

Note. Data from study $1 \mathrm{a}$ are above the diagonal line; data from study $1 \mathrm{~b}$ are below the diagonal. ${ }^{*} p \leq .05 ;{ }^{\dagger} p=.059$.

\section{Table 2}

Regression Analysis of Perceived Economic Inequality in Everyday Life and the Perceived Humanity Meta-Attributed to Poor and Rich Groups, Controlling for Participants'

Socioeconomic Status

\begin{tabular}{|c|c|c|c|c|}
\hline & \multicolumn{2}{|c|}{$\begin{array}{l}\text { Perceived humanity } \\
\text { meta-attributed to the poor }\end{array}$} & \multicolumn{2}{|c|}{$\begin{array}{l}\text { Perceived humanity } \\
\text { meta-attributed to the rich }\end{array}$} \\
\hline & $\beta(S E)$ & $95 \% \mathrm{CI}$ & $\beta(S E)$ & $95 \% \mathrm{CI}$ \\
\hline Spain (1a) & \multicolumn{2}{|c|}{$F(2,407)=3.16^{*}, R^{2}=.015$} & \multicolumn{2}{|c|}{$F(2,407)=3.55^{*}, R^{2}=.017$} \\
\hline Perceived economic inequality & $-2.02(.963)^{*}$ & {$[-3.91 ;-.124]$} & $2.10(.789)^{*}$ & {$[.549 ; 3.65]$} \\
\hline Participants socioeconomic status & $-.878(.747)$ & {$[-2.35 ; .591]$} & $-.226(.612)$ & {$[-1.43 ; 978]$} \\
\hline Mexico (1b) & \multicolumn{2}{|c|}{$F(2,403)=3.81^{*}, R^{2}=.019$} & \multicolumn{2}{|c|}{$F(2,403)=4.34^{*}, R^{2}=.021$} \\
\hline Perceived economic inequality & $-2.29(1.05)^{*}$ & {$[-4.36 ;-.21]$} & $2.24(.80)^{*}$ & {$[.66 ; 3.81]$} \\
\hline Participants socioeconomic status & $-.670(.42)$ & {$[-1.50 ; .16]$} & $.26(.32)$ & {$[-.37 ; .90]$} \\
\hline
\end{tabular}

Note. Coefficients are unstandardized. ${ }^{*} p \leq .05$.

\section{Discussion}


Those participants who perceived daily inequalities seemed to be relatively more aware of their society's tendency to dehumanize poor people and to humanize rich people, whereas those who did not perceive such inequities reported a narrower tendency to dehumanize poor people and to humanize rich people within their society. The results of these metaperception studies were consistent with previous results that indicated people directly perceived poor groups as being less evolved (i.e., having less HU) than rich groups (Sainz, Martínez, Rodríguez-Bailón, \& Moya, 2019). Additionally, individuals' SES did not play a prominent role in this matter as it did in previous research on similar contexts (Sainz, Martínez, Moya, \& Rodríguez-Bailón, 2019). Thus, people's recognition (i.e., metaperception) of the humanity levels ascribed to rich and poor people seemed to be independent of individuals' standing.

In short, acknowledging daily inequalities seems to relate to a stronger metaperceptions of poor people as dehumanized and rich people as humanized. Nevertheless, our studies relied on correlational data. Therefore, we performed additional experimental studies to deepen our understanding. In these studies, we manipulated the factor of perceived economic inequality to evaluate its effect on the metaperception that people tend to dehumanize poor people and humanize rich people in their society.

\section{Studies 2A and 2B}

In Studies $2 \mathrm{~A}$ and $2 \mathrm{~B}$, we sought to confirm the results of Studies $1 \mathrm{~A}$ and $1 \mathrm{~B}$ concerning the relationship between perceived economic inequality in everyday life and the metaperception of humanity while manipulating the former variable directly. We expected that a higher level of perceived economic inequality would lead to an increased recognition that poor people are dehumanized (Hypothesis 1) and rich people are humanized (Hypothesis 2) within the society. 
Preregistration can be found online:

https://osf.io/b5ukc/?view_only=5feb6db6d8944783aec9b31f3d85938a

\section{Method}

\section{Participants}

We computed the sample size for a small effect size (repeated MANCOVA, $f=.15$, $\alpha=.05,80 \%$ power; Faul et al., 2009). We required a minimum of 194 participants. Our final sample consisted of 320 Spanish (Study 2A; 225 females, 91 males, 4 others; $M_{\text {age }}=27.01$, $S D=10.13$ ) and 330 Mexican participants (Study 2B; 207 females, 122 males, 1 other; $\left.M_{\text {age }}=20.95, S D=6.06\right)$. We recruited participants for Study $2 \mathrm{~A}$ in the same way as in Study 1A. In Study 2B, we recruited university students to answer the survey in the laboratory in exchange for course credits. Participants were asked to complete a survey about how they would perceive their life if they moved to a different society. Once they agreed to participate, they were presented with the scenario described below:

\section{Manipulation of Perceived Economic Inequality}

We invited the participants to imagine that they were settling in a new neighborhood within a new society called Mazimba (see Jetten et al., 2015). Therefore, they needed to make some decisions (e.g., purchasing a house and car, selecting a vacation destination) and to familiarize themselves with locations in the area. They then received a description of Mazimba's socioeconomic structure, which comprises three distinct groups. Adapting previous procedures that manipulated economic inequality (Sánchez-Rodríguez et al., 2019), we varied the distance between the society's three socioeconomic groups (from poorest to wealthiest) based on the experimental conditions. Participants were assigned to one of two experimental conditions. In the low perceived economic inequality condition, income was distributed more equally among 
Group 3 (the poorest, earning 30,000 Mazimba dollars [M\$] per month), Group 2 (40,000 M\$ per month), and Group 1 (50,000 M\$ per month). In the high perceived economic inequality condition, the respective group incomes were 5,000 M\$ (Group 3), 40,000 M\$ (Group 2), and 150,000 M\$ (Group 1) per month. As in previous studies (see Sánchez-Rodríguez et al., 2019), in both experimental conditions, we told participants that they belonged to Group 2, the middleincome group.

To reinforce the material differences between socioeconomic groups, we presented participants with a selection of cars, houses, and vacation destinations that they could purchase as they started their new lives. The selection included items affordable by each socioeconomic group (e.g., very basic houses for Group 3, luxury mansions for Group 1). The items also varied between conditions. For instance, in the low economic inequality condition, the houses shown for Groups 1, 2, and 3 were quite similar, whereas in the high economic inequality condition, there was a clear difference between houses for socioeconomic Group 3 (shacks) and Group 1 (mansions). The materials were adapted from Sainz, Martínez, Moya, et al. (2020).

Finally, to reinforce the distribution of resources within the neighborhood, participants were given information on their neighbors from various socioeconomic groups. Pictures of restaurants, parks, grocery stores, and images of the neighborhood streets were displayed. These resources and locations differed based on the experimental conditions. For example, in the high economic inequality condition, we presented one picture of a luxury restaurant and one of a poor street food stall; participants in the low economic inequality condition saw two similar middleclass establishments. Please see the supplementary information for a full disclosure of the materials used in the manipulation.

\section{Manipulation Checks}


Participants answered the following manipulation check items. First, they were asked to which socioeconomic group in Mazimba they had been assigned, with answers ranging from Group 1 to Group 3. Second, as a manipulation check for perceived economic inequality, we adapted the scale of economic inequality in everyday life (e.g., "In my new neighborhood in Mazimba, I know people of very different levels of economic status"; Spain $\alpha=.960$; Mexico $\alpha=.962$; García-Castro et al., 2019) used in the previous studies. Answers ranged from 1 (completely disagree) to 7 (completely agree).

\section{Dehumanization, Socioeconomic Status, and Demographics}

We asked participants were asked to rate the extent to which they thought people would humanize or dehumanize poor and rich groups (i.e., metaperceptions) based on the information they had been given about Mazimba society (Kteily et al., 2015). Moreover, we measured participants' SES using the 10-step ladder (Adler et al., 2000) so we could include it as a covariate. Finally, we requested demographic information about the participants' gender, age, and nationality, after which we thanked them and provided a debriefing.

\section{Results}

Our results confirmed the manipulation's effectiveness, as nearly all participants identified the socioeconomic group to which they were assigned correctly $(99.4 \%$ in the Spanish sample; $99.1 \%$ in the Mexican sample). Furthermore, participants in the low economic inequality condition perceived less inequality (Spain: $M=5.13, S D=1.44$; Mexico: $M=4.93, S D=1.46$ ) than did those in the high inequality condition (Spain: $M=6.21, S D=1.37$; Mexico: $M=5.74$, $S D=1.58)$. The differences were significant for both the Spanish sample, $t(318)=6.83$, $p<.001, d=.77$, and the Mexican sample, $t(328)=4.75, p<.001, d=.53$. 
Second, we carried out MANCOVA analyses to compare the metahumanity ascribed to poor and rich groups (within-subject factors) as a function of the low versus the high level of economic inequality (between-subject factors) while controlling for participants' SES in both samples (Figure 1). In the Spanish sample, the results indicated significant differences between the metahumanity ascribed to poor people, $F(1,319)=27.85, p<.001, \eta_{p}^{2}=.081$, and that ascribed to rich people $F(1,319)=6.22, p=.013, \eta_{p}^{2}=.019$, as a function of the level of economic inequality, confirming Hypotheses 1 and 2. High economic inequality increased participants' metaperception of the humanity gap. The results for poor groups were as follows: lower meta-dehumanization in the low inequality condition $(M=45.84, S D=24.97)$ compared with the high inequality condition $(M=31.80, S D=22.62), t(318)=5.28, p<.001, d=.59$. In contrast, rich groups were accorded greater metahumanity in the high inequality condition $(M=79.05, S D=19.21)$ than in the low inequality condition $(M=73.69, S D=18.93)$, $t(318)=2.51, p=.013, d=.28$. SES had a small effect on the degree of metahumanity ascribed to poor groups in that higher SES was related to higher perceived humanity, $F(1,319)=19.97$, $p<.031, \eta_{p}^{2}=.059$, but it had no effect on the degree of metahumanity ascribed to rich people, $F(1,319)=.103, p=.748$.

Similarly, in the Mexican sample, the results indicated differences in the degree of metahumanity ascribed to poor people, $F(1,329)=8.02, p=.005, \eta_{p}^{2}=.024$, and rich people $F(1,329)=6.17, p=.013, \eta_{p}^{2}=.019$, as a function of the level of economic inequality (Hypotheses 1 and 2). Again, the humanity gap was greater in the high inequality condition, as shown the results we obtained for poor people (low inequality condition, $M=49.46, S D=24.45$; high inequality condition, $M=40.95, S D=26.82), t(328)=2.98, p=.003, d=.33$, and for rich people (low inequality condition, $M=77.17, S D=19.34$; high inequality condition, $M=82.01$, 
$S D=16.44), t(328)=4.75, p=.015, d=.27$. SES has a small effect on the level of metahumanity ascribed to poor people (i.e., higher participants SES results in the attribution of more humanity to the poor), $F(1,329)=4.64, p=.032, \eta_{p}^{2}=.014$, but not that ascribed to rich people, $F(1,329)=.306, p=.580$.

\section{Discussion}

The results of Studies 2A and 2B demonstrated experimentally that higher levels of daily life inequality increase individuals' metaperception that their society tends to dehumanize poor people and humanize rich people. In particular, these results emphasize that differences in humanity scores between experimental conditions seem to be larger in the case of poor people than in the case of rich people. Finally, within these studies, individuals' SES seems to play a more consistent role in the meta-humanity ascribed to poor people than in that ascribed to rich people.

In our final pair of studies, we extended our previous findings by implementing a new manipulation that enabled us to isolate the effect of perceived inequality from another potentially influential variable: the society's perceived level of economic development or wealth (Mols \& Jetten, 2017). In this sense, we are aware that certain social variables such as a society's globalization or overall wealth level can influence people's attitudes (Caluori et al., 2020; Vasilopoulou \& Talving, 2020). Thus, in the following studies we raised concerns about how people's metaperceptions of materially deprived groups and affluent groups differ when the perceptions of the society's overall material conditions (i.e., the wealth of the country) vary (Jetten et al., 2017). Specifically, we considered perceptions of inequality unlikely to have the same influence on metaperceptions of the humanity gap between poor and rich people in 
societies that are perceived as wealthy and developed compared with those that are perceived as poor and underdeveloped. 


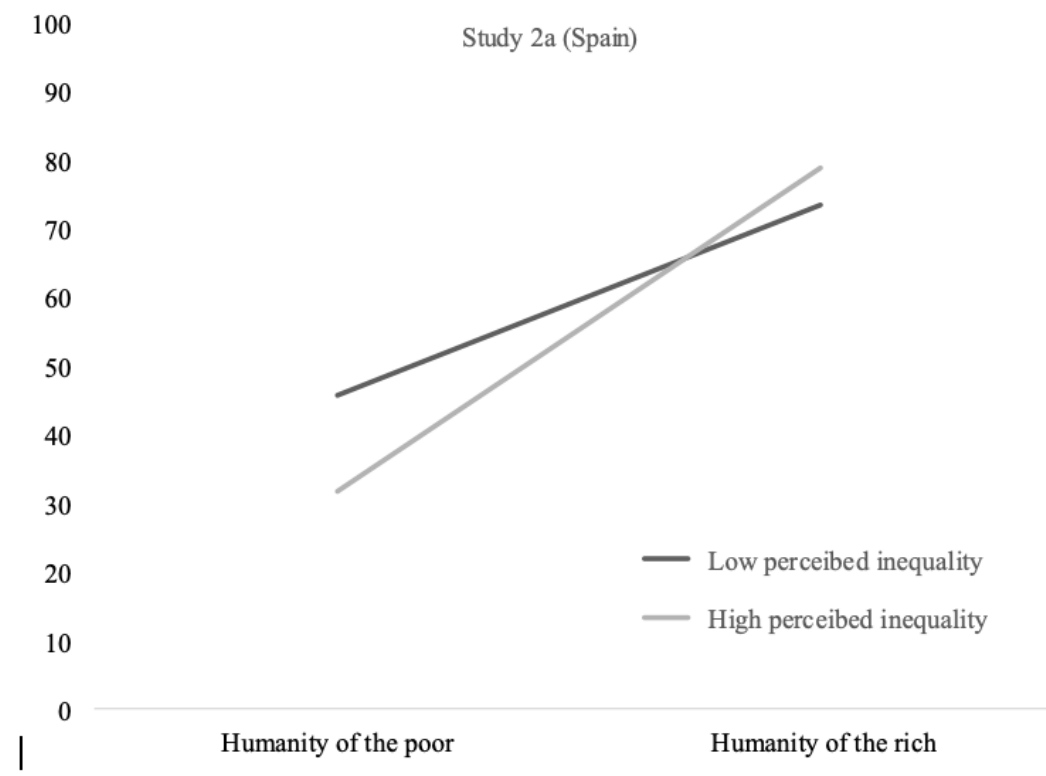

100

90

80

70

60

50

40

30

20

10

Humanity of the poo

Humanity of the rich

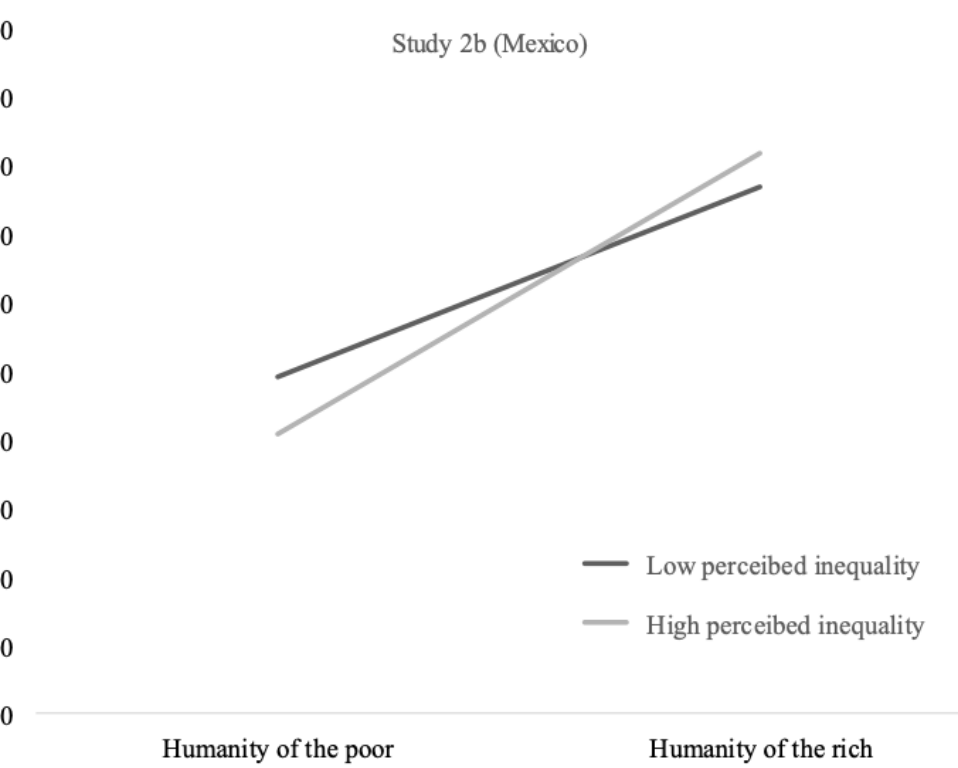

\section{Figure 1}

Differences in the Meta-Attribution of Humanity to Poor and Rich Groups Based on Perceived Economic Inequality Levels in Everyday Life for Studies $2 A$ (Spain) and $2 B$ (Mexico) 


\section{Studies 3A and 3B}

We conducted two additional experimental studies to explore the possible interplay between perceived economic inequality and a society's perceived economic development level (i.e., the relative wealth of the nation) in affecting the metahumanity ascribed to poor and rich groups. This was necessary because previous research has indicated the importance of considering how inequality might interact with other socioeconomic contextual features of a society (e.g., economic development or gross domestic product; Wilkinson \& Pickett, 2010) in affecting people's attitudes. We know, for instance, that a society's level of globalization can cause differences in how prejudice is exhibited between countries with low and high inequality (Caluori et al., 2020). Thus, the tendency to metadehumanize poor people might differ in contexts perceived as less developed or poor (i.e., where most residents live below or near the poverty line) compared to those in highly developed or wealthy contexts (i.e., where most residents sufficient access to goods and resources). Specifically, modifying a society's overall socioeconomic conditions (e.g., when all individuals in a society are seen as poor or rich) could modify individuals' attitudes toward groups at both extremes of the social ladder. For instance, poor people in a poor country (i.e., people living in conditions of absolute poverty) might be considered less human than poor people living in a wealthy country (i.e., people living in conditions of relative poverty). Moreover, exploring how metadehumanization might appear not only as a function of perceived inequality in a society, but also in relation to the level of wealth in a society can provide better insight into the role inequality plays in the process of metadehumanization, as well as how other societal factors might also contribute to this dynamic.

Furthermore, in this study, we aimed to isolate the effect of inequality or perceptions of development from the participants' personal preferences or ideological position on economic 
inequality. Personal preferences and tolerance for inequality are important variables that can shape one's understanding of socioeconomic differences or trigger attitudes about income redistribution (Wiwad et al, 2019). Nevertheless, in this project, we focused specifically on the influence of perceived economic inequality rather than preferences about economic inequality. Thus, when performing experimental manipulations on perceived inequality and development or wealth levels, we included as a covariate not only the participants' SES, as in previous studies, but also the participants' tolerance of economic inequality.

In this pair of studies, we predicted that we would replicate the previously identified effect of higher perceived economic inequality in producing a tendency to metadehumanize poor people (Hypothesis 1A) and metahumanize rich people (Hypothesis 2A). Moreover, we also predicted an effect of the perceived level of economic development: greater metadehumanization of poor groups in settings of low perceived economic development (i.e., poor societies;

Hypothesis 1B) and greater metahumanization of rich groups in societies with high perceived economic development (i.e., wealthy societies; Hypothesis 2B). Preregistration can be found online: https://osf.io/uj3ew/?view_only=b09b789b3bb34dcd95775166baa315c8

\section{Method}

\section{Participants}

We computed the sample size for a small effect size (repeated MANCOVA, $f=.15$, $\alpha=.05,80 \%$ power; Faul et al., 2009). G-power analysis indicated that we required a minimum of 489 participants to achieve sufficient power. The final sample consisted of 548 Spanish (Study 3A; 354 females, 190 males, 4 others; $\left.M_{a g e}=26.31, S D=9.87\right)$ and 509 Mexican (Study 3B; 280 females, 227 males, 2 others; $\left.M_{\text {age }}=23.73, S D=5.69\right)$ participants. We recruited participants online from the general population. In Study 3A, individuals participated in exchange for 
inclusion in a raffle for a prize of 100 euros. In Study 3B, which we conducted via Prolific Academic, we paying each participant $£ 1.10$.

\section{Experimental Setting}

We asked participants to imagine themselves settling in a new neighborhood. They were told that in this society, most people belong to one of three income groups, of which Group 1 comprised the society's wealthiest members and Group 3 comprised the poorest, and that they were members of Group 2 (middle-class). Then, we randomly assigned them to one of the four experimental conditions. Please the supplementary information for the full materials.

\section{Manipulation of Perceived Economic Inequality}

We implemented a manipulation similar to that used in the previous studies. Participants were invited to imagine that they were settling in a new neighborhood within a new society called Mazimba. They then received a description of Mazimba's socioeconomic groups. We varied the distance between the society's three socioeconomic groups based on the experimental conditions. In low perceived economic inequality condition, income was distributed more equally between Group 1 (the wealthiest) and Group 3 (the poorest). In the high perceived economic inequality condition, income was distributed more unequally between Groups 1 and 3 .

Furthermore, participants received information about local amenities (e.g., restaurants, supermarkets), public spaces (e.g., parks, streets), and their neighbors. As in the previous studies, we used these stimuli to communicate high or low perceived economic inequality in everyday life. Participants in the low economic inequality condition viewed pictures of two similar supermarkets or information about two neighbors with similar SES. Meanwhile, participants in the high economic inequality condition viewed pictures of two very different supermarkets-a 
street food market and a luxury establishment_ or information about two neighbors with highly different SES, one of whom is poor and the other of whom is wealthy.

\section{Manipulation of Perceived Economic Development}

To manipulate the level of economic development in the fictitious society, we modified the material conditions of the neighborhood (e.g., parks, restaurants, streets) and the society's overall wealth (i.e., poor versus rich society). To do so, we gave participants in the low development condition (i.e., poor society) a description of a neighborhood with run-down areas such as poorly maintained parks or streets with low-income houses. Moreover, to create the impression of low economic development in this condition, we described members of the society's wealthiest group as having their basic needs met, but not in a way that would typically cause them to be considered rich. On the other hand, in the high development condition (i.e., rich society), participants received information describing a neighborhood with luxurious public spaces and well-manicured homes and other locations. Furthermore, in this condition, even the poorest group had sufficient resources and adequate living conditions, whereas members of Group 1 had a massive amount of income.

The interplay between the manipulations of economic inequality and economic development led to the creation of four fictitious neighborhoods with the following income ranges: (a): unequal and developed (M\$50,000-M\$200,000 per month), (b) unequal and underdeveloped (M\$500-M\$50,000 per month), (c) equal and developed (M\$80,000-M\$100,000 per month), and (d) equal and underdeveloped (M\$10,000-M\$30,000 per month).

\section{Manipulation Checks}

Participants answered the following manipulation check items. First, they answered the question, “To which group were you assigned?” by indicating Group 1, 2, or 3. They then 
answered a question about perceived economic inequality: "In general, are the resources in your new neighborhood unequally distributed (i.e., there is a huge income gap between Groups 1 and 3) or equally distributed (i.e., there is a narrow income gap between Groups 1 and 3)?” Finally, they answered a question about perceived economic development: "In general, how poorly or well developed do you consider Mazimba as a society?" Answers were provided on a scale ranging from 1 (completely equal/extremely poor) to 7 (completely unequal/extremely rich).

\section{Dehumanization, Socioeconomic Status, Tolerance of Inequality, and Demographics}

We included the blatant metadehumanization measure included in Studies 1A and 1B and Studies 2A and 2B (Kteily et al., 2015). Participants were asked to rate the extent to which they thought people would humanize or dehumanize the poorest and wealthiest groups (i.e., metaperception), respectively, in the society to which they were assigned. Additionally, we sought to test the effect of our manipulation without interference from the participants' real-life SES or their personal preferences regarding inequality. Thus, we measured participants' SES using the 10-step ladder (Adler et al., 2000), and we assessed their level of tolerance for inequality using five items taken from Wiwad et al. (2019). A sample item is "Economic inequality is causing many of the world's problems." Answers were given on a scale ranging from 1 (completely disagree) to 7 (completely agree; Study 3A: $\alpha=.733$; Study 3B: $\alpha=.637$ ). This enabled us to use both SES and tolerance of inequality as covariates in the analysis. Next, we requested demographic information about gender, age, and nationality, and we ended by thanking and debriefing the participants.

\section{Results}

Our results confirmed the effectiveness of the manipulations. Virtually all participants correctly identified the socioeconomic group to which they were assigned (Study 3A: 98.9\%; 
Study 3B: 98.4\%). They correctly perceived the society's level of inequality, Study 3A: low inequality condition, $M=2.89, S D=1.48$; high inequality condition, $M=5.74, S D=1.51$; $t(546)=22.33, p<.001, d=1.90$; Study 3B: low inequality condition, $M=2.97, S D=1.44$; high inequality condition, $M=5.67, S D=1.26 ; t(507)=22.44, p<.001, d=2.07$. In addition, they correctly perceived its level of development, Study 3A: low development condition, $M=2.30$, $S D=1.16$; high development condition, $M=5.46, S D=1.33 ; t(546)=29.58, p<.001, d=2.60$; Study 3B: low development condition, $M=2.39, S D=1.23$; high development condition, $M=5.65, S D=1.12 ; t(507)=31.21, p<.001, d=2.67$.

To test our hypotheses, we carried out MANCOVA analyses to compare the metahumanity ascribed to poor and rich groups (within-subject factors) as a function of the experimental manipulations (between-subject factors) in each sample. We controlled for participants' SES and tolerance of inequality in the analyses (see Table 3).

Our results regarding the meta-attribution of humanity to poor people in the Spanish sample indicated a main effect of inequality (i.e., poor people were metadehumanized more in the high inequality condition than in the low inequality condition), a main effect of development (i.e., poor people were meta-dehumanized more in the low development condition than in the high development condition), and a significant interaction between inequality and development. This explorative interaction effect highlighted the fact that poor groups were more often metaperceived as less human in highly unequal and low development contexts than in the other experimental conditions. We found a similar pattern of results in the Mexican sample with the main effect of inequality (i.e., poor people were metadehumanized to a greater extent in the high inequality condition than in the low inequality condition) and a main effect of development (i.e., poor people were metadehumanized to a greater extent in the low development condition than in 
the high development condition). However, in this sample, the explorative interaction effect between inequality and development did not reach significance. Finally, the covariates did not affect the metahumanity ascribed to poor people, SES: Study $3 \mathrm{~A}, F(1,548)=.708, p=.400$, $\eta_{p}^{2}=.001 ;$ Study 3B, $F(1,509)=.006, p=.939, \eta_{p}^{2}=.001 ;$ tolerance of inequality: Study $3 \mathrm{~A}$ $F(1,548)=.000, p=.989, \eta_{p}^{2}=.001 ;$ Study $3 \mathrm{~B}, F(1,509)=.019, p=.891, \eta_{p}^{2}=.001$. Please see the supplementary materials for alternative analysis.

In both samples, results regarding the meta-attribution of humanity to rich people indicated no main effect of inequality, but they did indicate a main effect of development (i.e., rich people were metahumanized more often in the high development condition than in the low development condition) and a significant interaction between inequality and development. This explorative interaction effect indicated that rich groups were metaperceived as more human in the low inequality and high development contexts than in the other experimental conditions (see Figure 2). These results remained true even when the covariates were included in the analysis, SES: Study $3 \mathrm{~A}, F(1,548)=.30, p=.579, \eta_{p}^{2}=.001$; Study $3 \mathrm{~B}, F(1,509)=10.79, p=.001$, $\eta_{p}^{2}=.021$; tolerance of inequality: Study $3 \mathrm{~A}, F(1,548)=11.99, p=.001, \eta_{p}^{2}=.022$; Study $3 \mathrm{~B}$, $F(1,509)=.195, p=.659, \eta_{p}^{2}=.001$

\section{Discussion}

In these studies, we implemented an experimental manipulation that allowed us to isolate the effect of the perceived economic inequality from the economic development when examining people's meta-attribution of humanity to poor and rich groups. This contributes to the understanding of how not only perceived inequality, but also a society's wealth, might play a role 
in the tendency to perceive dehumanization. Once again, the two studies, conducted with samples in two very different socioeconomic contexts, yielded similar results. 


\section{Table 3}

Effects of the Manipulations of Economic Inequality and the Economic Development on Attributions of Metahumanity to Poor and Rich Groups, Controlling for Participants' Socioeconomic Status and Tolerance of Inequality

Spain (3a)

Humanity meta-attributed to the poor

Humanity meta-attributed to the rich

Mexico (3b)

Humanity meta-attributed to the poor

Humanity meta-attributed to the rich

\begin{tabular}{|c|c|c|c|c|c|c|c|}
\hline \multicolumn{2}{|c|}{ Inequality (Main effect) } & \multicolumn{2}{|c|}{ Development (Main effect) } & \multicolumn{4}{|c|}{ Inequality x Development (Interaction effect) } \\
\hline $\begin{array}{c}\text { Low } \\
\text { inequality }\end{array}$ & $\begin{array}{c}\text { High } \\
\text { inequality }\end{array}$ & $\begin{array}{c}\text { Low } \\
\text { development }\end{array}$ & $\begin{array}{c}\text { High } \\
\text { development }\end{array}$ & $\begin{array}{l}\text { Low inequality, } \\
\text { low-development }\end{array}$ & $\begin{array}{l}\text { High inequality, } \\
\text { high development }\end{array}$ & $\begin{array}{c}\text { Low inequality, } \\
\text { high development }\end{array}$ & $\begin{array}{l}\text { High inequality, } \\
\text { low development }\end{array}$ \\
\hline
\end{tabular}

$$
F_{(1,548)}=13.43, p<.001, \eta_{p}^{2}=.024 \quad F_{(1,548)}=7.41, p=.007, \eta_{p}^{2}=.013
$$

$35.78(24.56)$

$41.75(26.14)$

$42.11(24.31)$

$F_{(1,548)}=4.46, p=.035, \eta_{p}^{2}=.008$

$$
F_{(1,548)}=.089, p=.766, \eta_{p}^{2}=.001 \quad F_{(1,548)}=5.87, p=.016, \eta_{p}^{2}=.011
$$

$$
79.44(22.13) \quad 79.06(18.52) \quad 77.28(21.42) \quad 81.07(19.19)
$$

$74.95(24.23)$

$40.08(24.04)$

$43.41(28.03)$

$29.81(23.35)$

$$
F_{(1,548)}=8.15, p=.004, \eta_{p}^{2}=.015
$$

$$
78.65(18.87) \quad 83.45(19.28)
$$

$79.48(18.22)$

$$
F_{(1,509)}=5.25, p=.022, \eta_{p}^{2}=.010 \quad F_{(1,509)}=22.37, p<.001, \eta_{p}^{2}=.043
$$

$$
45.19(26.78) \quad 39.80(24.55) \quad 37.19(24.29) \quad 47.90(26.24)
$$

$41.11(25.35)$

$$
F_{(1,509)}=1.41, p=.236, \eta_{p}^{2}=.003
$$

$$
F_{(1,509)}=1.06, p=.304, \eta_{p}^{2}=.002 \quad F_{(1,509)}=8.29, p=.004, \eta_{p}^{2}=.016
$$

$80.46(20.68) \quad 82.10(15.87) \quad 79.19(20.66) \quad 83.36(15.73)$

(2)

$76.53(24.56)$
$46.61(24.72)$

$49.09(27.62)$

$33.36(22.66)$

$$
F_{(1,509)}=3.99, p=.046, \eta_{p}^{2}=.008
$$

$82.43(16.19) \quad 84.22(.15 .31)$

$81.79(16.61)$ 
Study 3a (Spain)

90

80

70

60

50

40

30

20

10

0

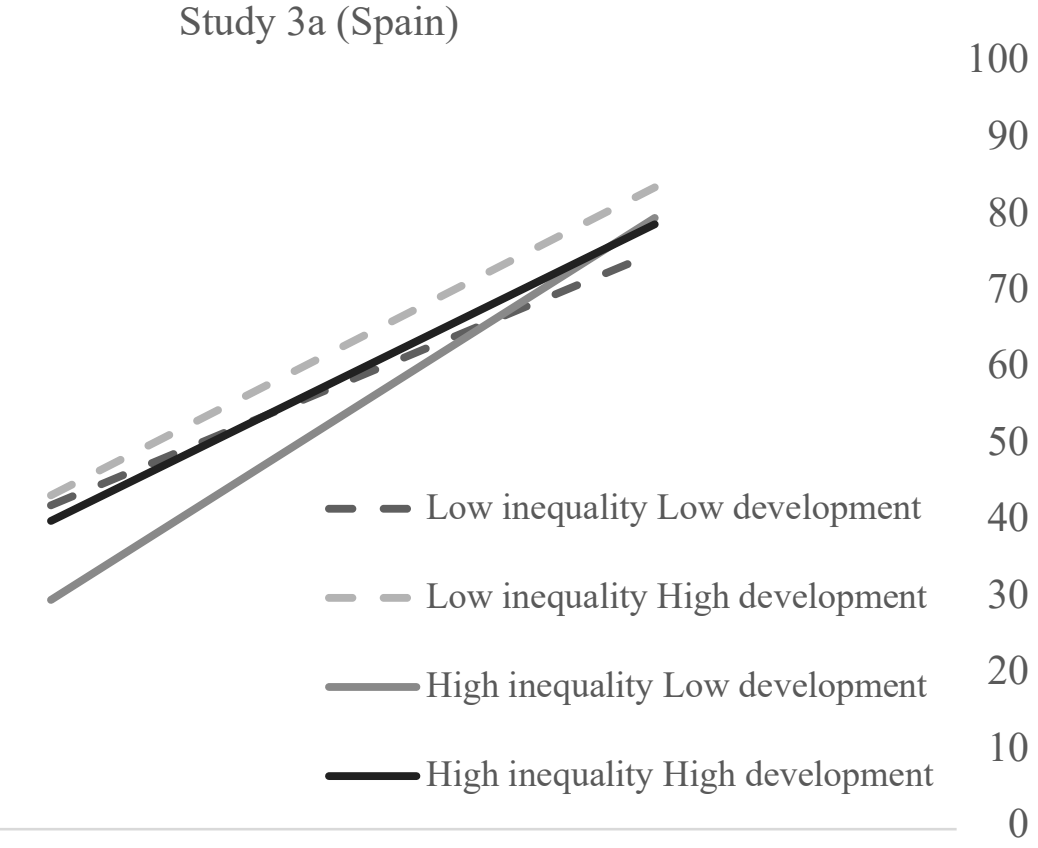

Humanity of the poor

Humanity of the rich
00

90

80

70

60

50

40

30

20

10

0
Study 3b (Mexico)

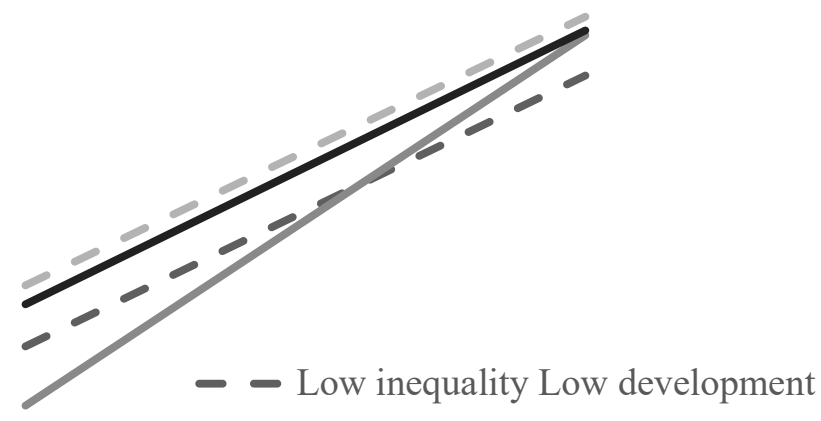

- Low inequality High development

- High inequality Low development

- High inequality High development

Humanity of the poor

\section{Humanity of the rich}

\section{Figure 2}

Differences in the Attribution of Metahumanity to Poor and Rich Groups Based on the Perceived Economic Inequality Level

(Low versus High) and Perceived Development Level (Low versus High) for Studies $3 A$ (Spain) and 3B (Mexico) 
First, a greater perceived level of economic inequality was associated with an increased tendency to metadehumanize poor people (Hypothesis 1A), but not to metahumanize rich people (Hypothesis 2A). This lack of effect of the metahumanity regarding rich people was unexpected when we compared the results with those of the previous studies. Therefore, we concluded that increasing economic inequality also increased metaperception of the humanity gap between poor and rich groups, but mainly through increased metadehumanization of those at the bottom of society.

Second, results from the manipulation of the society's economic development level (i.e., the wealth of the society) highlighted an interesting pattern of complementary results. Poor people were metadehumanized to a greater extent in the low development condition (i.e., in a poor society), whereas rich groups received higher metahumanity scores in the high development condition (i.e., in a wealthy society; Hypotheses $1 \mathrm{~B}$ and $2 \mathrm{~B}$ ). This exploratory pattern of results indicated that the people recognize the tendency to dehumanize poor people when scarcity (i.e., low development or poverty) is salient, but they assign higher HU cores to rich people when wealth (i.e., high development) is the norm.

Additionally, an explorative interaction effect appeared in the tendency to metadehumanize poor and rich people. Metadehumanization of poor groups prevailed in unequal and underdeveloped societies, whereas equal and developed societies enhanced the metahumanity ascribed to rich people. This shows how inequality and a society's wealth level can lead to specific metaperception paths regarding humanity. This pattern of results should be studied further to understand how society-level perceptions might drive other related consequences to dehumanization explored in previous research (e.g., support for redistribution, attributions about poverty or wealth). 
Finally, these effects remained significant even when controlling for participants' SES or their tolerance of economic disparities. These results indicate that perceptions of inequality and economic development or wealth can affect the attribution of to a greater extent than individual economic or ideological variables do.

\section{General Discussion}

The present research was aimed at demonstrating the influence of perceived economic inequality in daily contexts on the perceived tendency to metadehumanize poor people and metahumanize rich people within a society. Across two correlational and four experimental studies, we provided empirical evidence for how perceived inequality affects the tendency to recognize that poor people are dehumanized and rich people humanized within the society. This tendency appears regardless of participants' SES and preferences for economic inequality, but it interacts with other societal perceptions, such as the perceived level of economic development or relative wealth within a society.

As García-Castro et al. (2019) noted, perceived economic inequality in their surrounding contexts affects people's understanding of the society's level of inequality as a whole (e.g., attitudes toward redistribution, attributions about poverty and wealth). In our studies, individuals who perceived higher inequality levels in their daily experiences exhibited a larger humanity gap in their descriptions of poor and rich groups. In other words, they perceived greater metadehumanization of poor groups and metahumanization of rich groups. This robust pattern of results appeared in correlational studies in which the perception of inequality was measured (Studies 1A and 1B) and in experimental studies in which inequality was manipulated (Studies $2 \mathrm{~A}, 2 \mathrm{~B}, 3 \mathrm{~A}$, and $3 \mathrm{~B})$. This finding aligns partly with prior studies regarding how inequality is associated with the tendency to punish poor people and reward rich people (Hauser et al., 2019) 
and the relationship between inequality and the perception of poor people as lacking certain traits such as competence compared with rich people (Connor et al., 2020). Even when our research analysed metaperceptions rather than the direct attribution of traits to these groups. The present findings might bet attributable to the interplay between perceptions and metaperceptions rather than the direct tendency to humanize and dehumanize the extremes of the social ladder to a certain extent. Thus, these results indicate that increasing economic inequality has serious implications for how people at the extremes of the social hierarchy are perceived (Jetten et al., 2017).

In addition, our results indicated widening the humanity gap increases the metadehumanized perception of poor individuals in particular. In contrast, the effect of economic inequality is less consistent with regard to the metahumanity ascribed to rich people, as shown by the nonsignificant effect in Studies 3A and 3B. These findings indicate that inequality has a particularly pernicious effect in terms of harming poor people. Future studies might investigate this bias further by exploring alternative individual or structural variables that could predict the perceived humanity gap between poor and rich groups. In this regard, previous research has shown that direct attitudes toward rich people seem to differ from the negative attitudes that people hold toward poor people (Horwitz \& Dovidio, 2017). In this sense, people might hold explicitly negative attitudes about the gathering of wealth in the hands of a few individuals or groups, while implicitly favoring rich people because they desire to achieve an advantageous position in society. This ambivalence toward wealthy people and groups might indicate that metaperceptions about how poor and rich groups are evaluated within society might be driven by different factors (Hauser et al., 2019). In future studies, we might identify more precisely those distinct factors underlying the tendency to metadehumanize poor people or to metahumanize rich 
people. Greater understanding of these factors could support the development of interventions aimed at changing attitudes about economic inequality.

Apart from the previously mentioned points, the present project emphasizes the need to understand the mechanism that underlies the link between perceptions of inequality and metarecognition of humanity. On this matter, previous research highlights how economic inequality not only makes SES more salient (Peters et al., 2021), but also erodes social cohesion by promoting competition, reducing cooperation, increasing social vigilance, or favoring individual tendency toward self-enhancement (Cheng et al., 2021; Loughnan et al., 2011; Sánchez-Rodríguez et al., 2020). Thus, unequal scenarios are more likely to create conditions under which people perceive a hostile social climate compared to scenarios that are more equal. In the context of our study, perceptions of inequality might make people more willing to heighten existing shared beliefs about the idea that poor people or groups lack HU traits compared to rich people or groups. Therefore, higher perceived inequality levels might cause people to ascribe more value to social status or recognize a competitive social climate. Finally, this could make people more aware of the tendency to blame poor people for their poverty and praise rich people for their wealth, which might affect the metaperceptions of humanity ascribed to both groups. Nevertheless, future studies should explore in greater depth the possible mechanism linking perceived inequality with the widening of the perceived humanity gap between rich and poor people.

Furthermore, the present studies provide novel evidence for the interplay between perceptions of economic inequality and other variables such as a society's perceived economic development or wealth. Previous research has addressed the consequences of rising levels of economic inequality, mainly in highly developed countries (see Wilkinson \& Pickett, 2010). 
However, it is unlikely that attitudes toward poor and rich groups, or even attributions about poverty and wealth, will be the same in contexts perceived as underdeveloped (i.e., those where poverty is the rule) as in contexts perceived as developed (i.e., where people perceive more wealth in the society). The preliminary evidence shown here offers insights into how the effect of perceived economic inequality varies as a function of the perceived level of development: Poor people are most strongly metadehumanized in unequal and underdeveloped societies (but see Study 3B), whereas rich people are most strongly metahumanized in equal and developed societies. Therefore, the interplay between these factors seems to indicate that poor people are blamed more for their condition in less affluent societies and that rich people are perceived as more respected in societies perceived as wealthier. These findings show how perceptions of economic development (i.e., relative wealth or poverty of the whole society) interact in different ways with economic disparities (i.e., distance between wealthy and poor groups within a society) to reinforce the perceived humanity gap between groups. Our findings suggest the value of investigating how perceptions of the relative wealth or poverty of society influence people's lives and attitudes, along with perceptions of the distance between poor and rich groups. Poverty and poor people are not perceived equally when the whole society is perceived as underdeveloped, whereas wealth and rich people are not valued equally in societies perceived as wealthy. Future studies should acknowledge the importance of these findings because people's attitudes differ not only as a function of the social distance between groups, but also as a function of the starting point — perceptions of economic wealth — from which evaluations are made.

In addition, our findings did not show a consistent pattern of results regarding individual SES on the metaperception of the attribution of humanity. Even when, in some cases, SES did influence the meta-attribution of humanity to poor people, its effect did not erode the effect of 
perceptions (and the manipulations) of economic inequality on the current studies. On this matter, previous research that evaluated the direct attribution of humanity to poor and rich groups shows a similarly inconsistent pattern of results (see, for instance, Sainz, Loughnan, et al., 2020; Sainz, Martínez, Moya, \& Rodríguez-Bailón, 2019). Therefore, our evidence indicates that individual SES did not play a prevalent role in the matter of study. However, the existing evidence did not permit us to draw conclusions regarding the extent to which this lack of consistent effect is due to our sample characteristics (e.g., a lack of socioeconomic variability among our participants) or to more psychological foundations (e.g., a palliative effect among low-SES individual that justifies the status quo; Caricati \& Owuamalam, 2020). Further evidence is needed to properly understand why this individual variable has no effect on the metaattribution of humanity.

This research had some limitations. First, we examined our hypotheses by performing experimental studies based on the paradigm of a fictitious society (Jetten et al., 2015; SánchezRodríguez et al., 2019). Although this paradigm has several strengths and has been used widely in previous research, it suffers in terms of ecological validity. In an optimal situation, our hypotheses could have been tested using longitudinal data about changes in social perception as a function of country-level economic inequality and economic development. Second, in this project, when evaluating poor and rich people's humanity, we decided to measure metaperceptions by asking participants how they perceive that society views these groups. This procedure has been used widely in previous research on stereotypes (Fiske et al., 2002) as a strategy aimed at reducing the effects of social desirability in participants' evaluations. In the context of our study, we followed a similar strategy due to the blatant and explicit nature of the Ascent of Man scale (Kteily et al., 2015), which can make participants reluctant to give their 
opinions. One can argue that meta-perceptions are not equivalent to direct evaluations of individuals or groups. However, we acknowledge that direct or indirect evaluations are related to each other, and consequences, whether for poor or wealthy people, are equally negative regardless of whether they result from direct or indirect dehumanization. Nevertheless, further studies should clarify this issue by performing alternative studies. Third, when focusing on the tendency to metadehumanize groups, we did not acknowledge other potentially relevant factors. For instance, the present studies would have benefited from measuring attributions about poverty or wealth (Sainz, Martínez, Moya, \& Rodríguez-Bailón, 2019; Sainz, Martínez, Sutton, et al., 2020) or from analyzing the extent to which economic inequality also affects support for welfare policies or economic redistribution preferences (Sainz, Loughnan, et al., 2020). Future studies could examine the effects of economic inequality on all these variables that could promote the persistence of wealth gaps.

In general, our project has demonstrated the negative effect of economic inequality on people's lives, including the perception of metadehumanization by their neighbors. Societies that are more unequal foster the metadehumanization of poor people and the glorification of rich people. Given the detrimental effects of metadehumanization in several domains, our findings underscore the importance of implementing structural measures to reduce economic inequality within our societies.

\section{References}

Adler, N. E., Epel, E.S., Castellazzo, G. \& Ickovics, J. R. (2000). Relationship of subjective and objective social status with psychological and physiological functioning: Preliminary data in healthy white women. Health Psychology, 19(6), 586-592.

https://doi.org/10.1037/0278-6133.19.6.586 
Andersen, R. \& Fetner, T. (2008). Economic inequality and intolerance: Attitudes toward Homosexuality in 35 Democracies. American Journal of Political Science, 52(4), 942-958. https://doi.org/10.1111/j.1540-5907.2008.00352.x

Bobzien, L. (2019). Polarized perceptions, polarized preferences? Understanding the relationship between inequality and preferences for redistribution. Journal of European Social Policy, 30(2), 206-224. https://doi.org/10.1177/0958928719879282

Caluori, N., Brown-Iannuzzi, J. L., \& Cipolli, W. (2020). Economic inequality shapes the relationship between globalization and prejudice. Social Psychological and Personality Science, 12(6), 1082-1091. https://doi.org/10.1177/1948550620960929

Caricati L., \& Owuamalam, C. K. (2020). System justification among the disadvantaged: A triadic social stratification perspective. Frontiers in Psychology, 11, Article 40. https://doi.org/10.3389/fpsyg.2020.00040

Cheng, L., Hao, M., \& Wang, F. (2021). Beware of the 'bad guys': Economic inequality, perceived competition, and social vigilance. International Review of Social Psychology, 34(1), Article 9. http://doi.org/10.5334/irsp.497

Connor, P., Varney, J., Keltner, D., \& Chen, S. (2020). Social class competence stereotypes are amplified by socially signaled economic inequality. Personality and Social Psychology Bulletin, 47(1). 89-105. https://doi.org/10.1177/0146167220916640

Dawtry, R. J., Sutton, R. M., \& Sibley, C. G. (2015). Why wealthier people think people are wealthier, and why it matters: From social sampling to attitudes to redistribution. Psychological Science, 26(9), 1389-1400. https://doi.org/10.1177/0956797615586560

Durante, F., \& Fiske, S. T. (2017). How social-class stereotypes maintain inequality. Current Opinion in Psychology, 18, 43-48. http://doi.org/10.1016/j.copsyc.2017.07.033. 
Durante, F., Fiske, S. T., Kervyn, N., Cuddy, A. J., Akande, A. D., Adetoun, B. E., Adewuyi, M. F., Tserere, M. M., Ramiah, A. A., Mastor, K. A., Barlow, F. K., Bonn, G., Tafarodi, R. W., Bosak, J., Cairns, E., Doherty, C., Capozza, D., Chandran, A., Chryssochoou, X., ... Storari, C.C. (2013). Nations' income inequality predicts ambivalence in stereotype content: How societies mind the gap. British Journal of Social Psychology, 52(4), 726-746. http://doi.org/10.1111/bjso.12005

Elgar, F. J., \& Aitken, N. (2011). Income inequality, trust, and homicide in 33 countries. European Journal of Public Health, 21(2), 241-246. http://doi.org/10.1093/eurpub/ckq068

Esses, V. M., Veenvliet, S., Hodson, G., \& Mihic, L. (2008). Justice, morality, and the dehumanization of refugees. Social Justice Research, 21(1), 4-25. https://doi.org/10.1007/s11211-007-0058-4

Faul, F., Erdfelder, E., Buchner, A., \& Lang, A. (2009). Statistical power analyses using G*Power 3.1: Tests for correlation and regression analyses. Behavior Research Methods, 41, 1149-1160. http://doi.org/10.3758/BRM.41.4.1149

Fiske, S. T., Cuddy, A. J. C., Glick, P., \& Xu, J. (2002). A model of (often mixed) stereotype content: Competence and warmth respectively follow from perceived status and competition. Journal of Personality and Social Psychology, 82(6), 878902. https://doi.org/10.1037/0022-3514.82.6.878

Fiske, S. T, Moya, M., Russell, A. M., \& Bearns, C. (2012). The secret handshake: Trust in cross-class encounters. In S.T. Fiske, \& H. R. Markus (Eds.), Facing social class: How societal rank influences interaction (pp. 234-252). Russell Sage Foundation. 
García-Castro, J. D., Rodríguez-Bailón, R., \& Willis, G. B. (2020). Perceiving economic inequality in everyday life decreases tolerance to inequality. Journal of Experimental Social Psychology, 90, Article 104019. http://doi.org/10.1016/j.jesp.2020.104019

García-Castro, J. D. \& Willis, G. B., \& Rodríguez-Bailón, R. (2019). I know people who can and who cannot: A measure of the perception of economic inequality in everyday life. The Social Science Journal, 56(4), 599-608. http://doi.org/10.1016/j.soscij.2018.09.008.

García-Castro, J. D., García-Sánchez, E., Montoya-Lozano, M., \& Rodríguez-Bailón, R. (2021). The perception of economic inequality in Spain: My friends with the most and least money. Asian Journal of Social Psychology. Advance online publication. https://doi.org/10.1111/ajsp.12476

Goff, P. A., Eberhardt, J. L., Williams, M. J., \& Jackson, M. C. (2008). Not yet human: Implicit knowledge, historical dehumanization, and contemporary consequences. Journal of Personality and Social Psychology, 94(2), 292-306. https://doi.org/10.1037/00223514.94.2.292

Graafland, J., \& Lous, B. (2018). Income inequality, life satisfaction inequality and trust: A cross country panel analysis. Journal of Happiness Studies, 20, 1717-1737. https://doi.org/10.1007/s10902-018-0021-0

Haslam, N., \& Loughnan, S. (2014). Dehumanization and infrahumanization. Annual Review of Psychology, 65(1), 399-423. https://doi.org/10.1146/annurev-psych-010213-115045

Haslam, N., \& Stratemeyer, M. (2016). Recent research on dehumanization. Current Opinion in Psychology, 11, 25-29. https://doi.org/10.1016/j.copsyc.2016.03.009 
Hauser, O. P., Kraft-Todd, G. T., Rand, D. G., Nowak, M. A., \& Norton, M. I. (2019). Invisible inequality leads to punishing the poor and rewarding the rich. Behavioural Public Policy, 5(3), 333-353. https://doi.org/10.1017/bpp.2019.4

Heiserman, N., \& Simpson, B. (2017). Higher inequality increases the gap in the perceived merit of the rich and poor. Social Psychology Quarterly, 80(3), 243-253. http://doi.org/0190272517711919

Horwitz, S. R., \& Dovidio, J. F. (2017). The rich—love them or hate them? Divergent implicit and explicit attitudes toward the wealthy. Group Processes and Intergroup Relations, 20(1), 3-31. https://doi.org/10.1177/1368430215596075

Jetten, J., Mols, F., \& Postmes, T. (2015). Relative deprivation and relative wealth enhance antiimmigrant sentiments: The V-curve re-examined. PLOS ONE, 10(10), Article e0139156. http://doi.org/10.1371/journal.pone.0139156

Jetten, J., Wang, Z., Steffens, N. K., Mols, F., Peters, K., \& Verkuyten, M. (2017). A social identity analysis of responses to economic inequality. Current Opinion in Psychology, 18, 1-5. http://doi.org/10.1016/j.copsyc.2017.05.011

Kraus, M. W., \& Keltner, D. (2009). Signs of socioeconomic status: A thin-slicing approach. Psychological Science, 20(1), 99-106. https://doi.org/10.1111/j.1467-9280.2008.02251.x

Kteily, N., Bruneau, E., Waytz, A., \& Cotterill, S. (2015). The Ascent of Man: Theoretical and empirical evidence for blatant dehumanization. Journal of Personality and Social Psychology, 109(5), 901-931. https://doi.org/10.1037/pspp0000048

Kteily, N., Hodson, G., \& Bruneau, E. (2016). They see us as less than human: Metadehumanization predicts intergroup conflict via reciprocal dehumanization. Journal 
of Personality and Social Psychology, 110(3), 343-

370. http://dx.doi.org/10.1037/pspa0000044

Loughnan, S., Haslam, N., Sutton, R. M., \& Spencer, B. (2014). Dehumanization and social class: Animality in the stereotypes of "White trash," "Chavs," and "Bogans". Social Psychology, 45(1), 54-61. https://doi.org/10.1027/1864-9335/a000159

Loughnan, S., Kuppens, P., Allik, J., Balazs, K., de Lemus, S., Dumont, K., Gargurevich, R., Hidegkuti, I., Leidner, B., Matos, L., Park, J., Realo, A., Shi, J., Sojo, V. E., Tong, Y., Vaes, J., Verduyn, P., Yeung, V., \& Haslam, N. (2011). Economic inequality is linked to biased self-perception. Psychological Science, 22(10), 1254-

1258. https://doi.org/10.1177/0956797611417003

Mols, F., \& Jetten, J. (2017). The wealth paradox: Economic prosperity and the hardening of attitudes. Cambridge, UK: Cambridge University Press.

https://doi.org/10.1017/9781139942171

Patel, V., Burns, J. K., Dhingra, M., Tarver, L., Kohrt, B. A., \& Lund, C. (2018). Income inequality and depression: A systematic review and meta-analysis of the association and a scoping review of mechanisms. World Psychiatry, 17(1), 76-89.

https://doi.org/10.1002/wps.20492

Peters, K., Jetten, J., Tanjitpiyanond, P., Wang, Z., Mols, F., \& Verkuyten, M. (2021). The language of inequality: evidence economic inequality increases wealth category salience. Personality and Social Psychology Bulletin, 1-16. https://doi.org/10.1177/01461672211036627

Pickett, K. E., \& Wilkinson, R. G. (2015). Income inequality and health: A causal review. Social Science \& Medicine, 128, 316-326. https://doi.org/10.1016/j.socscimed.2014.12.031 
Pickett, K. E., Kelly, S., Brunner, E., Lobstein, T., \& Wilkinson, R. (2005). Wider income gaps, wider waistbands? An ecological study of obesity and income inequality. Journal of Epidemiology \& Community Health, 59(8), 670-674.

http://doi.org/10.1136/jech.2004.028795

Rufrancos, H. G., Power, M., Pickett, K. E., \& Wilkinson, R. (2013). Income inequality and crime: A review and explanation of the time-series evidence. Sociology and Criminology, 1(1): 103. https://doi.org/10.4172/2375-4435.1000103

Sainz, M., Loughnan, S., Martínez, R., Moya, M., \& Rodríguez-Bailón, R. (2020). Dehumanization of socioeconomically disadvantaged groups decreases support for welfare policies via perceived wastefulness. International Review of Social Psychology, 33(1): 12, 1-13. https://doi.org/10.5334/irsp.414

Sainz, M., Martínez, R., Moya, M., \& Rodríguez-Bailón, R. (2019). Animalizing the disadvantaged, mechanizing the wealthy: The convergence of socio-economic status and attribution of humanity. International Journal of Psychology, 54(4), 423-430. http://doi.org/10.1002/ijop.12485

Sainz, M., Martínez, R., Moya, M., Rodríguez-Bailón, R., \& Vaes, J. (2020). Lacking socioeconomic status reduces subjective well-being through perceptions of metadehumanization. British Journal of Social Psychology, 60(2), 470-489. http://doi.org/10.1111/bjso.12412

Sainz, M., Martínez, R., Rodríguez-Bailón, R., \& Moya, M. (2019). Where does the money come from? Humanizing high socioeconomic status groups promotes income inequality. Frontiers in Psychology, 10, 711. http://doi.org/10.3389/fpsyg.2019.00771 
Sainz, M., Martínez, R., Sutton, R. M., Rodríguez-Bailón, R., \& Moya, M. (2020). Less human, more to blame: Animalizing poor people increase blame and decrease support for wealth redistribution. Group Processes \& Intergroup Relations, 23(4), 546-559. https://doi.org/10.1177/1368430219841135

Sánchez-Rodríguez, Á., Rodríguez-Bailón, R., \& Willis, G. B. (2020). Economic inequality affects perceived normative values. Group Processes \& Intergroup Relations. https://doi.org/10.1177/1368430220968141

Sánchez-Rodríguez, Á., Willis, G. B, Jetten, J., \& Rodríguez-Bailón, R. (2019). Economic inequality enhances inferences that the normative climate is individualistic and competitive. European Journal of Social Psychology, 49(6), 1114-1127. https://doi.org/10.1002/ejsp.2557

Uslaner, E. M., \& Brown, M. (2005). Inequality, trust, and civic engagement. American Politics Research, 33(6), 868-894. https://doi.org/10.1177/1532673X04271903

Vaes, J., Leyens, J. Ph., Paladino, M. P., \& Pires-Miranda, M. (2012). We are human, they are not: Driving forces behind outgroup dehumanisation and the humanisation of the ingroup. European Review of Social Psychology, 23(1), 64-106. https://doi.org/10.1080/10463283.2012.665250

Vasilopoulou, S., \& Talving, L. (2020). Poor versus rich countries: A gap in public attitudes towards fiscal solidarity in the EU. West European Politics, 43(4), 919-943. https://doi.org/10.1080/01402382.2019.1641781

Wilkinson, R., \& Pickett, K. (2010). The spirit level: Why greater equality makes societies stronger. New York: Bloomsbury Press. 
Wiwad, D., Mercier, B., Maraun, M. D., Robinson, A. R., Piff, P. K., Aknin, L. B., \& Shariff, A. F. (2019). The support for economic inequality scale: Development and adjudication. PloS one, 14(6), Article e0218685. https://doi.org/10.1371/journal.pone.0218685 